JPE 10-4-15

\title{
Design of a Microcontroller Based Electronic Load Controller for a Self Excited Induction Generator Supplying Single-Phase Loads
}

\author{
Sarsing Gao ${ }^{\dagger}$, S. S. Murthy*, G. Bhuvaneswari*, and M. Sree Lalitha Gayathri** \\ ${ }^{*}$ Dept. of Electrical Engineering, Indian Institute of Technology, New Delhi, India \\ ** Oracle India Pvt. Ltd., Bangalore, India
}

\begin{abstract}
The generation of electric power using self excited induction generation (SEIG) is a viable option in remote and rural areas where grid electricity is not available. The generated voltage and frequency of these machines, however, varies with varying loads. This characteristic can be resolved either by adjusting the values of the excitation capacitance or by controlling the prime mover speed. Further, in a single-point constant power application, where the machines deliver a fixed amount of power, the electronic load controller (ELC) can be used to switch-in or switch-out a dump load whenever the consumer load decreases or increases respectively. This paper presents a detailed analysis and the design of a microcontroller based SEIG -ELC system intended for stand-alone pico hydro power generation. The simulated performance of the controller is supplemented by experimental results.
\end{abstract}

Key Words: Capacitor excitation, Dump load, Electronic load controller, Self excited induction generator

\section{INTRODUCTION}

The electrification of rural and remote locations is key to balanced development of a nation as electrical energy has become a basic necessity for a quality life today. Grid power is inadequate or unavailable in several areas, especially those in the remote and inaccessible locations of developing countries. The growing concerns for the environment, increasing costs, rapidly reducing fossil fuel resources and techno-economic difficulties in extending the existing power grid to remote locations, have compelled the use of locally available renewable energy resources. Naturally recycled resources such as wind, hydro, solar and bio-energy have been available for a long time although so far they have not been adequately utilized as a result of more attractive but pollution generating fossil fuels. However, efforts are on to utilize them especially in distributed and decentralized generation applications. This urgency is implicit in the recent "Copenhagen" declaration on emissions control to avert climate change and global warming. This global meeting also acknowledged the need to provide basic electricity to all humanity while addressing the above concerns. New technologies must be developed within this framework for the global good. Rural and remote communities need single-phase power mainly for lighting, fans and entertainment. It is, therefore, essential to develop

\footnotetext{
Manuscript received Mar. 24, 2010; revised May 24, 2010

† Corresponding Author: sarsing.gao@gmail.com

Tel: +91 11 26591092, Fax: +91 11 26581606, IIT Delhi

* Dept. of Electrical Engineering, IIT, India

** Oracle India Pvt. Ltd., India
}

a solution to power these pockets with user-friendly, cheap and rugged technology. The self-excited induction generator is an appropriate electrical machine for such distributed and decentralized power generation applications [1]. They are inexpensive, rugged and available off-the-shelf. Due to certain advantages such as higher output to weight ratio, higher efficiency and of-the-shelf availability, a three-phase machine can be operated on a C-2C connection for supplying singlephase loads [2]. The generated voltage and frequency of a SEIG, however, varies with varying loads. This characteristic can be resolved either by adjusting the values of the excitation capacitance or by controlling the prime mover speed [3]-[7]. Further, in a single-point constant power application, where the machine delivers a fixed amount of power, an ELC can be used to switch-in or switch-out a dump load whenever the main load decreases or increases, respectively [8]-[9]. The function of an ELC is to keep the effective output power at the SEIG terminals constant. The operating point of a SEIG is fixed such that it gives a rated output at rated conditions of voltage, current and speed. Furthermore, the variations in the consumer load are neutralized by the load controller by diverting the extra power to a dump load. An integrated ELC realized through the use of a star/polygon transformer with a VSC and a battery at its DC bus is found to be effective in voltage and frequency regulation for pico hydro applications [10]. This system is suitable for feeding three-phase four-wire loads.

This paper details the analysis and design aspects of a digitally controlled ELC for an SEIG feeding single-phase 
loads. The digital control is realized by means of a PIC $18 \mathrm{~F} 252$ microcontroller which provides a better performance with increased operational flexibility. Both simulation and hardware results are presented.

\section{SYSTEM CONFIGURATION AND PRINCIPLES OF OPERATION}

The proposed ELC is designed to operate on a delta connected three-phase induction machine rated at $7.5 \mathrm{~kW}, 230 \mathrm{~V}$, $26.2 \mathrm{~A}, 4$-pole, $50 \mathrm{~Hz}$ with a fixed operating power of $2.3 \mathrm{~kW}$ for feeding a single-phase load. A C-2C connection is adopted which facilitates the single-phase operation of a three-phase machine. The ELC consists of a diode rectifier and a chopper circuit connected in series with a dump load. The duty cycle of the IGBT switch is controlled depending on the variations in consumer load which eventually decide the amount of power to be dumped. The SEIG terminal voltage is used as a feedback signal to the control circuit after proper isolation and attenuation. The control action of the switch is carried out by means of a microcontroller which generates the PWM pulses based on the errors in the voltages being compared. Since the speed and hence the frequency is constant, the output power remains constant when the voltage is maintained at the rated value. The controller circuit works under the following conditions:

The AC voltage from the SEIG terminal is rectified by means of an uncontrolled bridge rectifier. An electrolytic capacitor is connected across the diode bridge rectifier to filter out the ripples. The dump load is designed such that when the duty cycle of the switch is unity, an operating power of 2.3 $\mathrm{kW}$ is diverted to it. A freewheeling diode is connected across the dump load for circulation of the stored energy in the dump load. The terminal voltage is stepped down and is clamped to a voltage proportional to the SEIG output with a DC offset. This analog voltage is fed to a PIC $18 \mathrm{~F} 252$ microcontroller which converts the input signal to a digital value using the on-the-chip ADC. A mathematical relation is developed to get an analog equivalent of the digital value given by the ADC. The microcontroller is programmed in such a way that the feedback voltage is compared with a reference value of $230 \mathrm{~V}$ for every 40 milliseconds and an error signal is generated. A PI controller is used to provide proper control without steady state errors or instability.

The PWM signal is fed to an opto-coupler, which isolates the power circuit and the control circuit. This signal drives the IGBT switch with an appropriate duty cycle. The schematic diagram of a three-phase SEIG in a C-2C connection feeding a single-phase load with a digitally controlled ELC is shown in Fig. 1.

Fig. 2 shows a block diagram of the microcontroller based digital control circuit of an ELC. The secondary output of the transformer acts as a voltage source for the opto-coupler which provides the necessary isolation for the gate driver circuit of the IGBT and the clamper circuit, the output of which is fed to the microcontroller. These secondary voltages are stepped down to the required values using voltage regulators. The clamper circuit and the design aspects of various other circuits

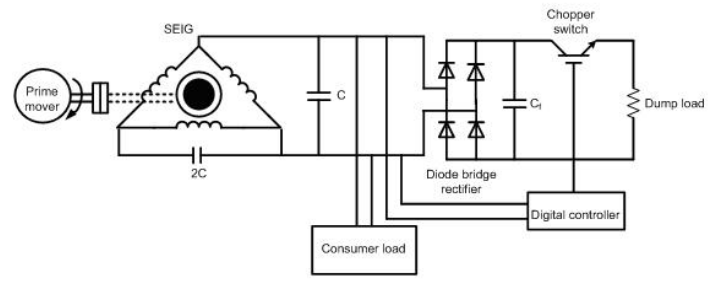

Fig. 1. Three-phase SEIG with ELC feeding 1-phase load.

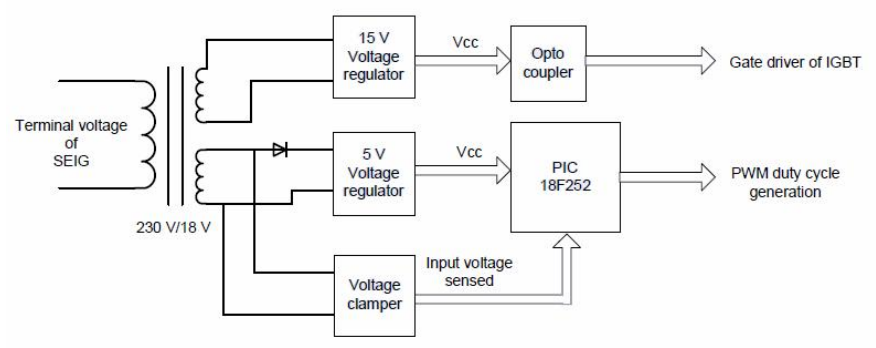

Fig. 2. Block diagram of microcontroller based digital control.

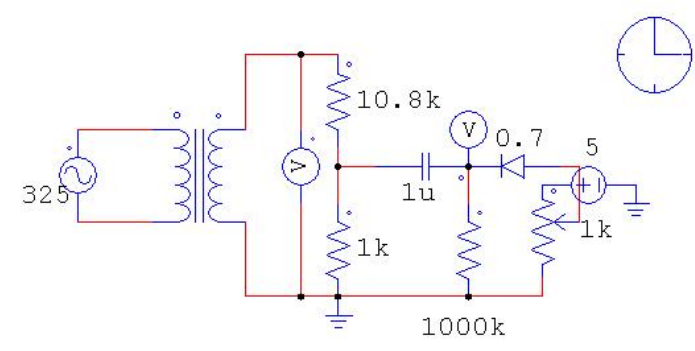

Fig. 3. Voltage clamper circuit.

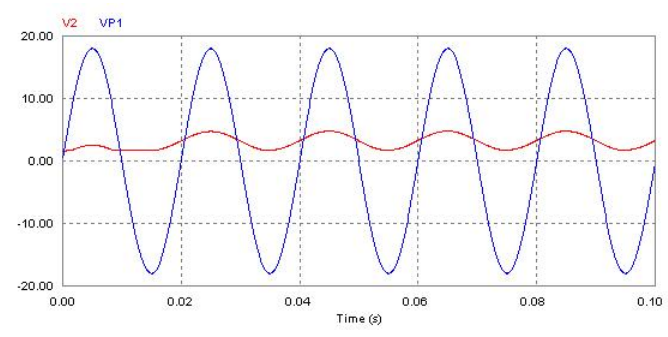

Fig. 4. Voltage input and output of the clamper circuit.

required for the proposed ELC are described in subsequent sections.

\section{A. Voltage clamper circuit}

The terminal voltage of the SEIG is stepped down to 18 $\mathrm{V}$ and the secondary voltage of the transformer is clamped to a positive value, less than $5 \mathrm{~V}$, using a voltage clamper circuit as shown in Fig. 3. This forms the input signal to the microcontroller. The input and output voltage of the clamper circuit is shown in Fig. 4.

\section{B. Design of the power circuit}

The voltage rating of the uncontrolled rectifier and the chopper switch will be the same and dependent on the rms value of the ac input voltage and the average value of the 


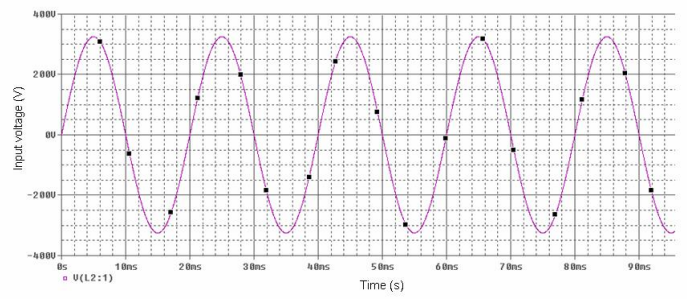

Fig. 5. Terminal voltage of SEIG fed to ELC.

output dc voltage. For a $2.3 \mathrm{~kW}$ load, the rms value of the input voltage is $230 \mathrm{~V}$ and the average value of the dc voltage is:

$$
V_{d c}=0.9^{*} V_{l}=0.9^{*}(230+10 \%)=270 \mathrm{~V} .
$$

The DC link capacitor will always get charged to the peak of the sinusoidal input voltage of the bridge rectifier. Therefore, $V_{d c}=325 \mathrm{~V}$.

The current rating of the single-phase uncontrolled rectifier and the IGBT switch is decided by the active ac input current and the average value of the dc current. The active component of the ac input current to the single-phase rectifier is calculated as:

$$
I_{d c}=\frac{P}{V_{l}}=\frac{2300}{230}=10 \mathrm{~A}
$$

In a single-phase uncontrolled rectifier, the distortion factor is 0.9 and the crest factor varies from 1.8 to 3 . The peak current is thus, calculated as:

$$
I_{\text {peak }}=\frac{10^{*} 2}{0.9}=22.22 \mathrm{~A} \text {. }
$$

The rating of the dump load resistance, $R_{d}$ is calculated as:

$$
R_{d}=\frac{(207)^{2}}{2300}=18.63 \Omega
$$

A PSPICE simulation is carried out to obtain the performance characteristics of the ELC. The maximum current that can be allowed to pass through the designed ELC is only 10 A.

\section{DC link capacitor}

A DC link capacitor is mainly used to reduce the ripple content in the output voltage of a rectifier. This, in turn, will provide a constant DC voltage to the chopper switch when failing which may damage the switch. When there is a sudden switch ON of the controller, the capacitor acts as a dead short circuit for awhile. As a result, there is a chance for the bridge rectifier to get damaged. Hence, a trade off value of $1000 \mu \mathrm{F}$ is chosen to reduce its charging current during the initial conditions and to reduce the ripple content of the DC voltage to an appreciable value. Figs. 5 and 6 show the terminal voltage of the SEIG fed to the ELC and the DC link capacitor voltage, respectively.

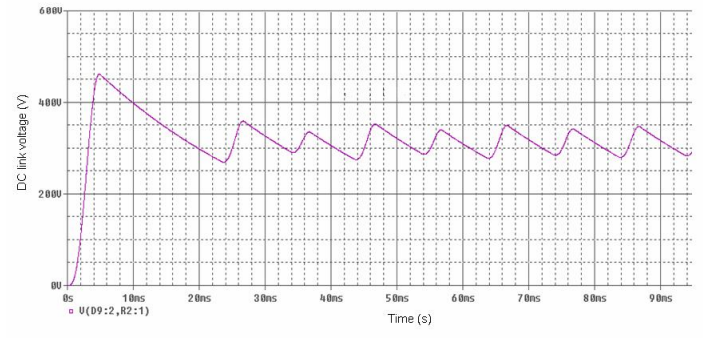

Fig. 6. DC link capacitor voltage.

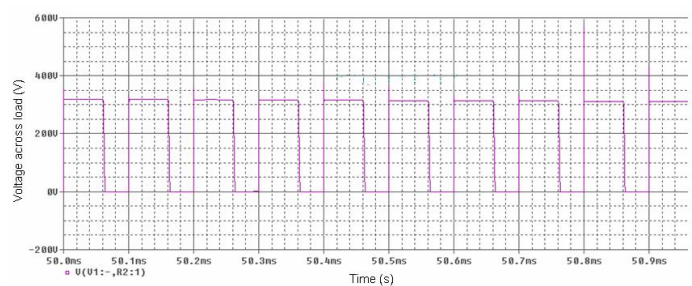

(a)

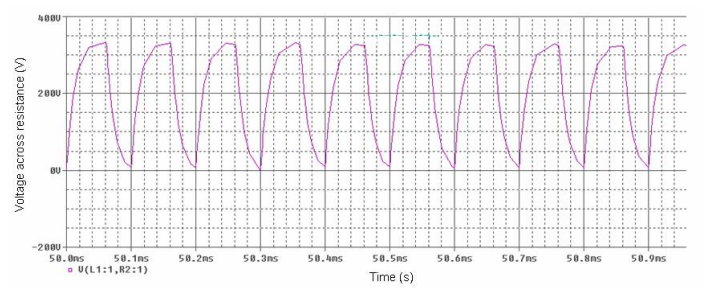

(b)

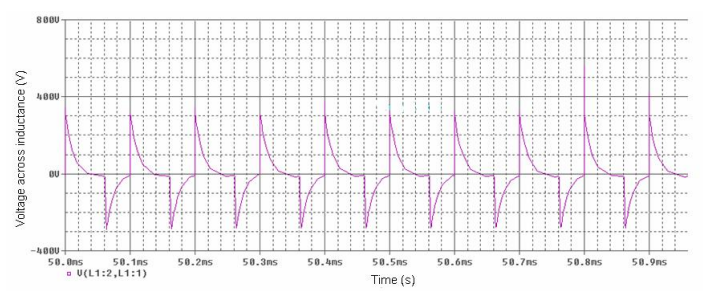

(c)

Fig. 7. Voltage across (a) dump load, (b) dump resistance and (c) dump stray inductance, $L_{s}$.

The rating of the dump resistor is selected as $18 \Omega, 12 \mathrm{~A}$ which can dump a power of $2.3 \mathrm{~kW}$ delivered by the SEIG. The resistance chosen is not purely resistive but contains some stray inductance due to which the dump load stores some energy when it is switched ON. Hence, there is a need to discharge its stored energy when it is switched OFF. Therefore, a free wheeling diode (FWD) of the fast recovery type is connected across the dump resistor in order to protect the chopper switch. Fig. 7 (a), (b) and (c) show the voltage waveforms across Rd with a stray inductance $L_{s}$. From these waveforms it can be observed that due to the presence of stray inductance in the dump resistor, energy is stored in the dump load when it is turned ON. This causes a high voltage spike across the dump load and the IGBT switch. Therefore, a FWD is connected across the dump load to arrest this problem. 


\section{Design of the snubber circuit}

A discharge suppressing RCD snubber is considered. The snubber circuit gets activated when the $V_{C E}$ of the IGBT starts to exceed the DC supply voltage.

The spike voltage when the IGBT is turned OFF is calculated as:

$$
V_{C E S P}=E_{d}+V_{F}+\left(-L_{s} \frac{d I_{c}}{d t}\right)=368 \mathrm{~V}
$$

where:

$E_{d}=$ the DC supply voltage

$V_{F}=$ the forward on-voltage

$I_{c}=$ the collector current at the IGBT turn-off

$L_{s}=$ the stray inductance

A polypropylene or decoupling capacitor is used in the snubber circuit and it is placed as close as possible to the IGBT switch in order to bypass the high frequency surge currents. The usage of decoupling capacitors, by providing a non inductive path during switching operation, eliminate severe voltage transients during switching and helps smooth out the circuit waveforms. Based on the circuit stray inductance $L_{s}$, the maximum switching current $I_{0}$, the DC rail voltage $V_{C C}$ and the allowable peak voltage $V_{p k}$, the snubber capacitance value is calculated as:

$$
C_{s n}=\frac{L_{s} I_{0}^{2}}{\left(V_{p k}-V_{c c}\right)^{2}}=0.22 \mu F .
$$

The snubber resistance discharges the electric charge accumulated in the snubber capacitor before the IGBT is next turned OFF. To discharge $90 \%$ of the accumulated energy by the next turn OFF, $R_{s n}$ must have a value given by:

$$
R_{s n} \leq \frac{1}{2.3 C_{s n} f}=200 \Omega
$$

The power dissipation loss caused by the resistance of this circuit is:

$$
R_{s n}=\frac{L_{s} I_{0}^{2} f_{s w}}{2}=144 W .
$$

The snubber resistance should not be set too low. Otherwise the snubber current will oscillate and the peak collector current at turn OFF will increase. Fig. 8 shows the voltage across the snubber resistance and the capacitor respectively.

Fig. 9 shows the average power dissipation in the snubber resistance, while Fig. 10 shows the currents in the snubber resistance and capacitor respectively.

\section{EXPERIMENTAL RESULTS}

Experimentation is carried out on a three-phase SEIG-ELC system feeding a single-phase load. A resistive load, which can be varied from 0 to $2.3 \mathrm{~kW}$ in steps, is used as the consumer load. Excitation capacitors of $C_{1}=50 \mu \mathrm{F}$ and $C_{2}=95 \mu \mathrm{F}$ are used such that the machine generates the rated voltage and the rated frequency. The controller is designed to keep the operating point at these conditions. The dump load is set

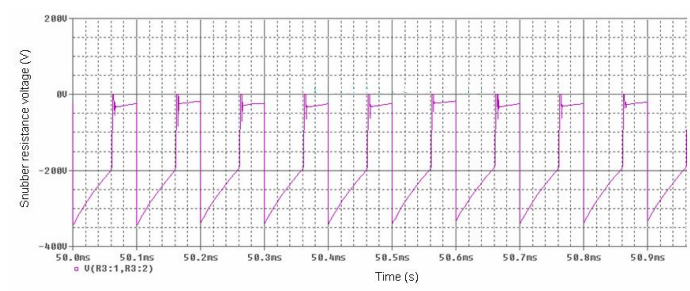

(a)

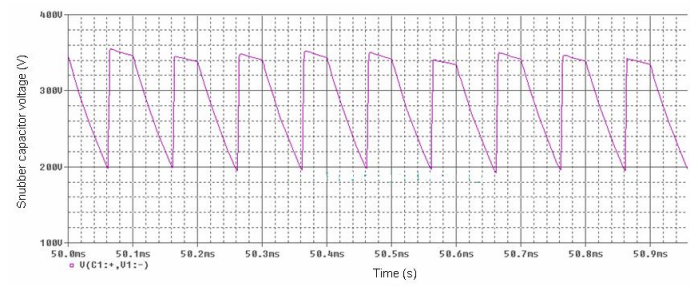

(b)

Fig. 8. Voltage across (a) snubber resistance (b) snuber capacitor.

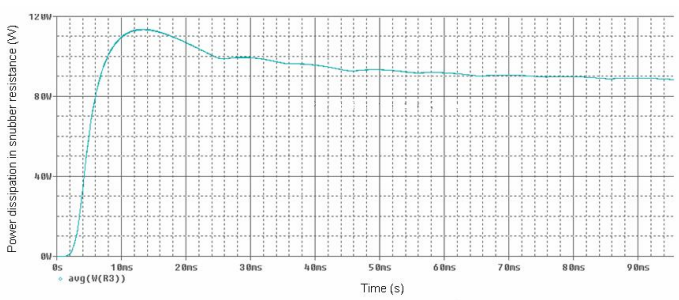

Fig. 9. Average power dissipation in the snubber resistance.

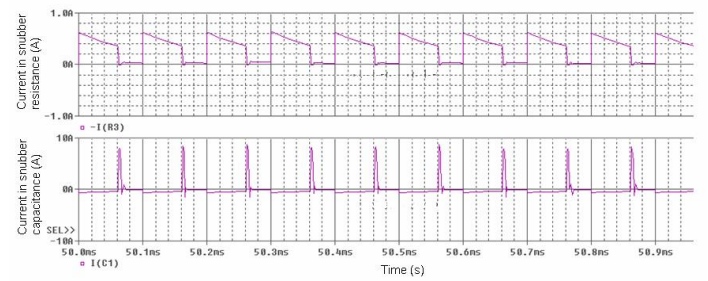

Fig. 10. Currents in snubber resistance and capacitor respectively.

as $2.3 \mathrm{~kW}$ in order to consume the entire consumer load when the chopper duty cycle is $100 \%$ i.e., when the consumer load is zero. The consumer load is turned $\mathrm{ON}$ and turned OFF in steps and the output voltage and power are observed to be constant. Fig. 11 shows the experimental waveforms of the input voltage, the DC link voltage and the input current of the ELC. Without a FWD, the spikes in the input current to the ELC are very high as shown in Fig. 12. This is due to the sudden turn ON and turn OFF which, in turn, is due to stray inductance in the dump load. This is eliminated by connecting a FWD, the waveform of which is shown in Fig. 13. Fig. 14 shows the experimental values of the load voltage, the current waveforms and the output power of the SEIG-ELC at the selected operating point of $2.3 \mathrm{~kW}$.

The power circuit is turned on at $1.4 \mathrm{~s}$ and thus, the generated no load voltage of the SEIG drops slightly down to $228 \mathrm{~V}$. As can be seen, fairly good voltage regulation is achieved when the load is connected to the machine at $2 \mathrm{~s}$ and then disconnected at 4.5 s. Figs. 15 and 16 show the simulated performance of the proposed ELC when the main load is 


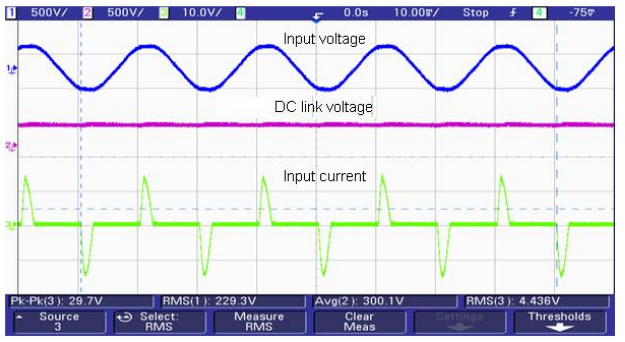

Fig. 11. Experimental waveforms of input voltage, DC link voltage and input current of ELC.

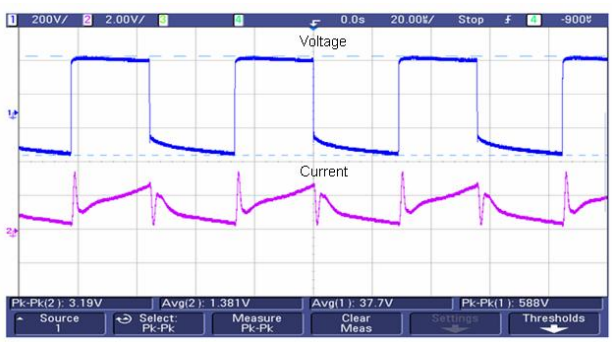

Fig. 12. Experimental waveforms of voltage and current of ELC without FWD.

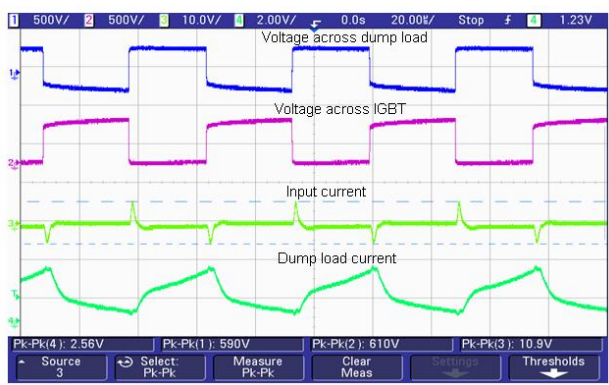

Fig. 13. Experimental waveforms of voltage and current of ELC with FWD.

reduced to $60 \%$ and $40 \%$ of the full load value, respectively for resistive and inductive loads. The experimental results are shown in Figs. 17 and 18. The performance of the ELC is shown to agree well with the simulated results. It can be seen that the proposed voltage controller is effective in terms of sharing a constant generated power of $2.3 \mathrm{~kW}$ between the main load and the dump load as and when the main or consumer load is changed.

\section{CONCLUSIONS}

The developed microcontroller based ELC circuit is found to be reliable, compact and above all, cost effective. It provides a fast control action, that is invariably within 2 cycles. It also provides the flexibility for changing the PI control parameters for providing a duty cycle over a wide range. Hence, the same ELC can be used for different ratings of machines, including single-phase machines, by changing the PI control parameters in the program of the microcontroller. The developed scheme is tested with a three-phase SEIG system feeding a singlephase load which is able to give a voltage regulation of +/$5 \%$ which is good enough for standalone micro/pico hydro applications. The experimental results indicate that a SEIG

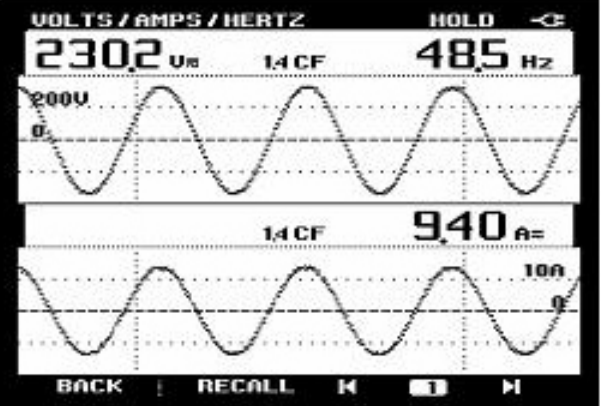

(a)

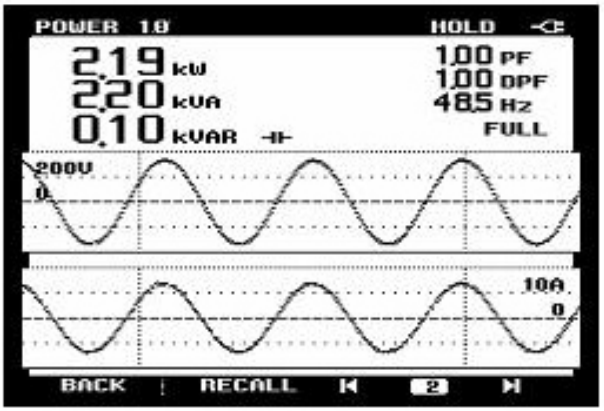

(b)

Fig. 14. (a) Load voltage and current waveforms of SEIG-ELC at the selected operating point $(2.3 \mathrm{~kW})$ and (b) Power output.

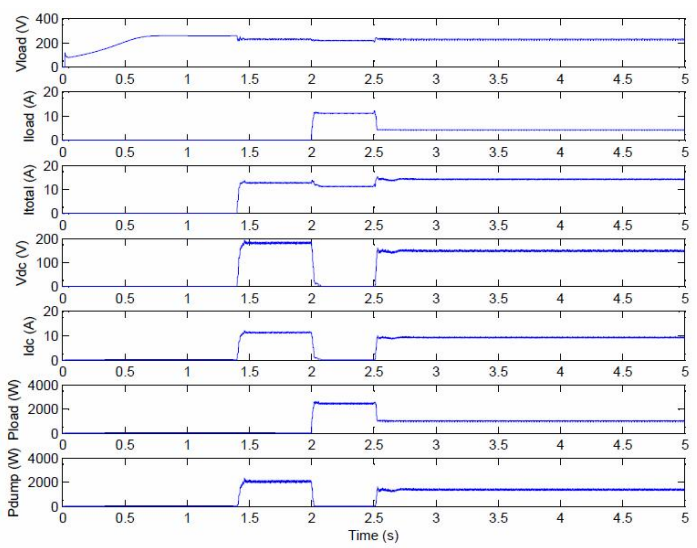

Fig. 15. Simulated values of voltage, current and power of the ELC when the main load is reduced by $60 \%$ of full load value at resistive load.

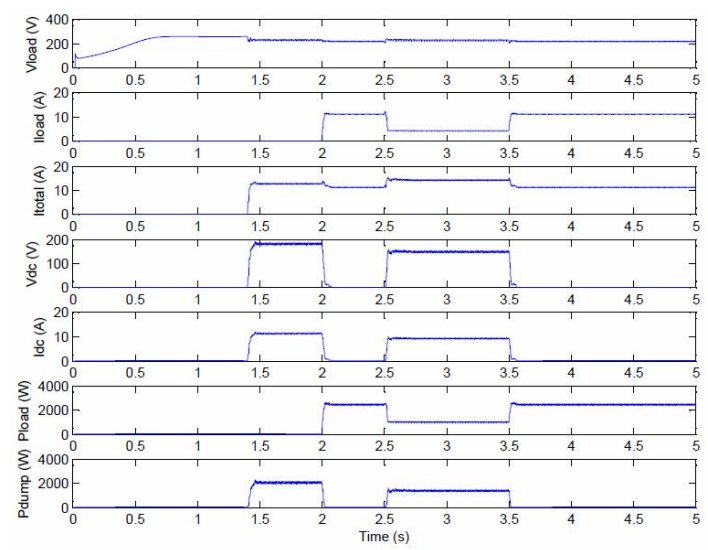

Fig. 16. Simulated values of voltage, current and power of the ELC when the main load is reduced by $40 \%$ of full load value at lagging PF load. 


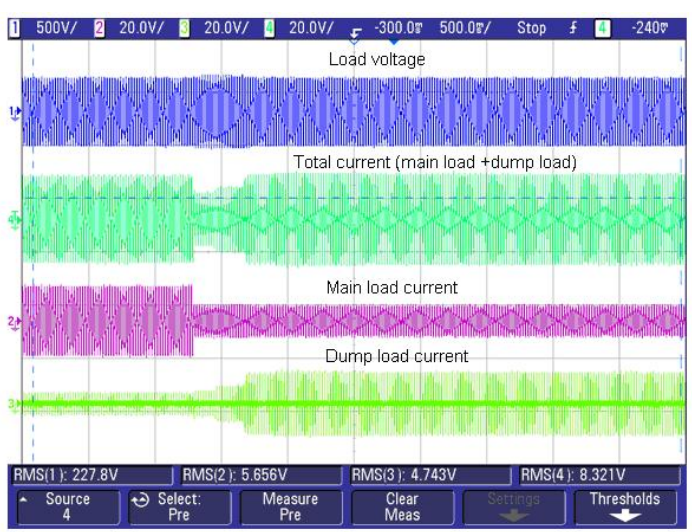

Fig. 17. Experimental waveforms of voltage and current when the main load is reduced by $60 \%$ of full load value at resistive load.

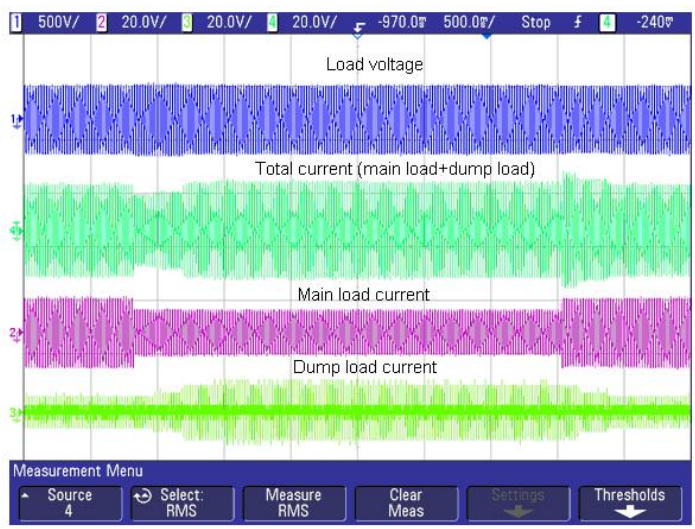

Fig. 18. Experimental waveforms of voltage and current when the main load is reduced by $40 \%$ of full load value at lagging PF load.

based system with a load controller can compensate for the varying consumer loads in the case of unity as well as lagging PF loads. Therefore, the proposed scheme is ideal for applications in low power stand-alone pico hydro systems where the generating system is normally subjected to resistive loads.

\section{APPENDIX}

\section{A. Machine data:}

$7.5 \mathrm{~kW}, 230 \mathrm{~V}, 26.2 \mathrm{~A}, 50 \mathrm{~Hz}$, 4-pole, delta connected induction machine, where $R_{s}=1 \Omega, R_{r}=0.77 \Omega$, and $X_{l s}=X_{l r}=1 \Omega$

\section{B. Prime mover characteristics:}

$$
T_{\text {shaft }}=\left(K_{1}-K_{2} \omega m\right) ; K_{1}=995.31 ; K_{2}=6.34
$$

\section{PI controller parameters:}

$$
K_{p}=0.25 ; K_{i}=1.5
$$

\section{REFERENCES}

[1] S. S. Murthy, O. P. Malik and A. K. Tandon, "Analysis of self excited induction generator," IET Proc., Vol. 129, No. 6, pp. 260-265, Nov. 1982.
[2] S.S. Murthy, B. Singh, S. Gupta, and B.M. Gulati, "General steady-state analysis of three-phase self-excited induction generator feeding threephase unbalanced load/single-phase load for stand-alone applications," IET Proc., Vol. 150, No. 1, pp. 49-55, Jan. 2003.

[3] J. B. Ekanayake, "Induction generators for small hydro schemes," Power Engineering Journal, Vol. 16, No. 2, pp. 61-67, Apr. 2002.

[4] S. S. Murthy, Rini Jose and Bhim Singh, "A Practical load controller for stand alone small hydro systems using self excited induction generator," in IEEE Proc. of PEDES for Industrial Growth, pp. 359-364, Dec. 1998.

[5] D. Henderson, "An advanced electronic load governor for control of micro hydro electric generation," IEEE Trans. Energy Conversion, Vol. 13, No. 3, pp. 300-304, Sep. 1998.

[6] R. Bonert and S. Rajakaruna, "Self excited induction generator with excellent voltage and frequency control," IET Proc., Vol. 145, No.1, pp. 33-39, Jan. 1998.

[7] D. Joshi, K. S. Sandhu and M. K. Soni, "Constant voltage constant frequency operation for a self excited induction generator," IEEE Trans. Energy Conversion, Vol. 21, No. 1, pp. 228-234, Mar. 2006.

[8] Bhim Singh, S. S. Murthy and S. Gupta, "Analysis and design of electronic load controller for self excited induction generator," IEEE Trans. Energy Conversion, Vol. 21, Vol. 1, pp. 285-293, Mar. 2006.

[9] S. S. Murthy, G. Bhuvaneswari, Sarsing Gao and M. S. L. Gayathri, "Performance analysis of a self excited induction generator with digitally controlled electronic load controller for micro hydel power generation," in IEEE Proc. of POWERCON, pp. 1-6, Oct. 2008.

[10] Bhim Singh and V. Rajagopal, "Battery energy storage based voltage and frequency controller for isolated pico hydro systems," Journal of Power Electronics, Vol. 9, No. 6, pp. 874-883, Nov. 2009.

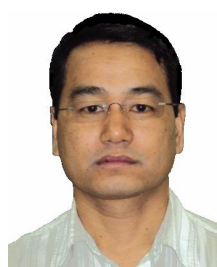

Sarsing Gao is working as a faculty member at the North Eastern Regional Institute of Science \& Technology [NERIST], Itanagar, India. He is currently pursuing his Ph.D. in the Department of Electrical Engineering, IIT, Delhi, India. He is a Student Member of IEEE and a Life Member of ISTE, India. His areas of interest include renewable energy and induction generators as well as electrical machines and drives.

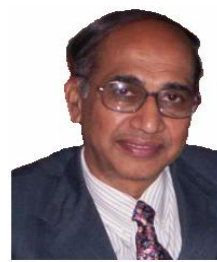

S. S. Murthy is the CEA Chair Professor in the Department of Electrical Engineering, IIT, Delhi, India. He was a Visiting Professor at Ryerson University, Toronto and the University of Calgary, Canada. He has nearly 40 years of teaching and research experience. $\mathrm{He}$ is a Life Senior Member of IEEE and a Fellow of IET, UK. He was the Director of the National Institute of Technology, Surathkal, India and the Electrical Research and Development Association, Baroda, India. He has worked as a visiting consultant in major Electrical Industries such as General Electric and Kirloskar Electric in Bangalore, India. His areas of interest are renewable energy and induction generators as well as electrical machines and drives.

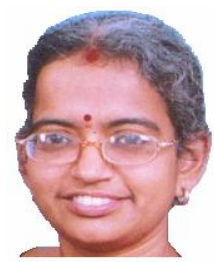

G. Bhuvaneswari is working as an Associate Professor in the Department of Electrical engineering, IIT, Delhi, India. She is a Senior Member of IEEE and a Fellow of IETE, India. Her areas of interest are power electronics, electrical machines and drives, power supplies, power quality and HVDC transmission.

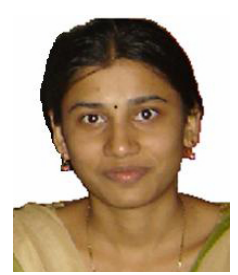

M. Sree Lalitha Gayathri is working as a Senior Technical Management Executive with Oracle India Pvt. Ltd., Bangalore, India. Her areas of interest are power electronics and electrical machines and drives. 